\title{
Food Quotient Assessments Using One-Week Dietary Records and Food Frequency Questionnaires of Young Japanese Runners
}

\author{
Akiko UchizAWA ${ }^{1}$, Airi FunAYAmA ${ }^{1}$, Haruka OSUmi ${ }^{1}$, Yasushi ENOMOTO ${ }^{2}$, Simeng Zhang ${ }^{3}$, \\ Kumpei TOKUYAMA ${ }^{3}$, Naomi $\mathrm{OMI}^{2}$ and Hiroyuki SAGAYAMA ${ }^{2, *}$ \\ ${ }^{1}$ Graduate School of Comprehensive Human Science, University of Tsukuba, 1-1-1 Tennodai, \\ Tsukuba, Ibaraki 305-8577, Japan \\ ${ }^{2}$ Faculty of Health and Sport Sciences, University of Tsukuba, 1-1-1 Tennodai, \\ Tsukuba, Ibaraki 305-8577, Japan \\ ${ }^{3}$ International Institute for Integrative Sleep Medicine (WPI-IIIS), University of Tsukuba, \\ 1-1-1 Tennodai, Tsukuba, Ibaraki 305-8575, Japan
}

(Received October 14, 2021)

\begin{abstract}
Summary The food quotient (FQ), which is the rate of macronutrient composition calculated from daily meals, can equal the respiratory quotient over a long term. The FQ is needed to estimate the total energy expenditure (TEE) in doubly labeled water studies. Usually, dietary records (DR) are used for dietary assessment in clinical nutritional studies; however, the DR method's disadvantage is that it takes time to calculate the results. In comparison, the food frequency questionnaires (FFQ) method is a simple and quick way to calculate results. This study aimed to assess the FQ in Japanese runners, and to compare the two dietary assessment methods, DR and FFQ, to examine whether FFQ is useful in calculating the FQ in healthy young adults and runner. The study consisted of 27 runners and 22 healthy young adults. The participants recorded and took pictures all their meals for $1 \mathrm{wk}$ and provided the FFQ for the same week. The FQ was calculated using the proportions of proteins, fats, carbohydrates, and alcohol. There were no significant differences between the FQs of the runners 0.867 (male: 0.873 , female: 0.863 ) and the healthy young adults 0.871 (male: 0.875 , female: 0.867 ) according to the DR methods. There were no differences in the FQs between DR and FFQ methods for all groups. A significant correlation between the FQs $(r=0.502, p<0.01)$, estimated using the DR, and the FQs estimated using the FFQ was observed. These results suggest that use of the FFQ method can provide comparable data for runners and healthy young adults.
\end{abstract}

Key Words doubly labeled water, dietary intake, DR, FFQ, dietary assessment

The doubly labeled water (DLW) method has been used to estimate the total energy expenditure (TEE) in free-living conditions (1). This method can be useful in the determination of the energy requirements of athletes from the TEE (2). In the DLW technique, first, the rate of carbon dioxide production $\left(\mathrm{rCO}_{2}\right)$ is estimated, then the $\mathrm{rCO}_{2}$ is converted to the TEE using a respiratory quotient (RQ) or food quotient (FQ) (3-6). The RQ is calculated from the ratio of $\mathrm{CO}_{2}$ production to $\mathrm{O}_{2}$ consumption, and the $\mathrm{FQ}$ is calculated from the proportions of protein, fat and carbohydrate, or the protein, fat, carbohydrate, and alcohol in the meals. In humans under energy balance conditions, the $\mathrm{FQ}$ must equal the RQ, if the ratio of protein, fat and carbohydrate is not different in a long term $(7,8)$. The DLW technique generally adopts $\mathrm{FQ}$ as surrogate of $\mathrm{RQ}$ when measured $\mathrm{RQ}$ over 24-h is not available. The distribution of macronutrients in meals is different between countries or cultures, thus reference values can differ between countries. Individual FQs can also be calculated from dietary records.

${ }^{*}$ To whom correspondence should be addressed.
For example, the FQ is 0.86 in the U.S. (9), 0.83 in the U.K. (10), and 0.93 in Nepal (11). In Japan, it is 0.87 (12) and 0.86 (13) in healthy adults who are 20-59 and $64-87 \mathrm{y}$ in age, respectively.

In Japan, the composition of meals has changed over time because of the westernization of food (14). In addition, athletes can choose special diets to make their training more effective and to achieve their ideal body composition or weight for each competition (15), for example a high-fat diet $(16,17)$, and a high-carbohydrate diet (18). For some athletes, especially long-distance runners, their diet is important because their physical condition or body mass can affect their performance. Therefore, Japanese people may have different FQ depending on their age and characteristics, though the FQ in young Japanese athletes are not known.

Dietary intake and energy intake is often assessed using dietary assessment methods such as dietary records (DR) (19), food frequency questionnaires (FFQ) (20), self-administered diet history questionnaires (21), and $24 \mathrm{~h}$ dietary recalls (22). Usually, DR are used in the clinical nutritional studies field and are widely used for determining FQ. However, the DR are burdensome 
and annoying to use for both the dietitians and participants. Moreover, problems, such as omissions of entries and declarations, have been associated with its use. On the other hand, the FFQ are simple and quick methods for dietary assessment and have been used widely by participants including young adults, older adults, and athletes $(20,23,24)$. Furthermore, it has also been reported that the FFQ may be valid for the FQ calculation, considering its greater standardization and reduced potential for investigator bias (25). Athletes, in particular, require quick results of their dietary assessments in order to monitor in their training and dietary guidelines, i.e., the method that can provide feedback in a short time is desirable. This is also important for nutritional research.

Therefore, this study aimed to assess the FQ of Japanese runners in order to calculate the energy expenditure using the DLW method. In addition, the two dietary assessment methods, DR and FFQ, were compared to examine whether FFQ is useful for calculating the FQ in healthy young adults and runners.

\section{MATERIALS AND METHODS}

Participants. The study population consisted of 49 young adults, of which 27 were middle- and long-distance runners $(20.2 \pm 1.4 \mathrm{y})$, and 22 were non-athletes $(22.2 \pm 2.1 \mathrm{y})$ (Table 1$)$. We excluded patients with current medical conditions, metabolic diseases, and smoking habits. The participants did not use any medications that affected their glucose or lipid metabolism, and none had thyroid or heart diseases. All the participants who fulfilled the inclusion criteria participated in the study. The participants were living in Japan and volunteered via personal contact or word of mouth. All the measurements of the participating females with menstrual cycles were in their follicular phases. The study protocols were explained to all the participants, and they provided written informed consent for each procedure; the study was conducted in accordance with the Declaration of Helsinki. This study was approved by the Institutional Review Board of the University of Tsukuba, Faculty of Health and Sport Sciences (Ref No. Tai 019-41).

Body size and composition. The height was measured using a stadiometer. The body weight and body composition were measured using the bioimpedance method (BC-118E, TANITA Co., Tokyo, Japan) in the morning, after overnight fasting.

Dietary assessment. The participants recorded all their meal for $1 \mathrm{wk}$ and took pictures of all their meals and drinks using smart phones. The participants were instructed to take pictures of the meal along a $2.5 \mathrm{~cm}$ square marker. A well-trained registered dietician calculated the energy and macronutrient intake from the DR and the photographs. All DR were analyzed using computerized nutrient software based on the 2016 version (7th rev.) of the Standard Tables of Food Composition in Japan (Excel Eiyou-kun Version 8.0, Kenpakusha, Tokyo, Japan) (26). For a processed diet, the values listed on the food ingredient labels were used. The daily energy intake for each week was recorded using the FFQ
(FFQg version 5, Kenpakusha, Tokyo, Japan) with their meal pictures. The DR and FFQ were conducted for the same week.

Food quotient (FQ) and non-alcohol FQ. The FQ and non-alcohol FQ were calculated using two equations published by Black et al. (7) and Westerterp (8) as follows:

$\mathrm{FQ}=(\mathrm{P} \times 0.81+\mathrm{F} \times 0.70+\mathrm{C} \times 1.00+\mathrm{A} \times 0.67) / 100$

non-alcohol $\mathrm{FQ}=(\mathrm{P} \times 0.81+\mathrm{F} \times 0.70+\mathrm{C} \times 1.00) / 100$

The equations included protein, fat, carbohydrate, alcohol. Each percentage represented refers to the energy contribution against the total energy intake. The total energy intake calculated for protein for $4 \mathrm{kcal} / \mathrm{g}$, fat for $9 \mathrm{kcal} / \mathrm{g}$, carbohydrate for $3.75 \mathrm{kcal} / \mathrm{g}$ and alcohol for $7 \mathrm{kcal} / \mathrm{g}$ (7). The amounts of energy of protein, fat, carbohydrate, and alcohol were calculated by multiplying the amount of each nutrient $(\mathrm{g})$ by each energy conversion factor (kcal). The percentages of protein $(\mathrm{P})$, fat $(\mathrm{F})$, carbohydrate $(\mathrm{C})$, and alcohol $(\mathrm{A})$ were calculated from the total energy intake divided the energy of each nutrient. The FQ and non-alcohol FQ were calculated from the results of the DR and FFQ, respectively.

Literature review for Japanese non-alcohol FQ. To avoid any bias from the average non-alcohol FQ in our single laboratory, we reviewed reported dietary assessments from the Japanese National Health and Nutrition Surveys (2019) and nine published articles (27-35). The selection criteria for the articles were that the studies included healthy young Japanese and Japanese runners between 18-29 y, and that the articles presented only a dietary survey without any interventions.

Statistical analysis. The sample size was calculated using the correlation analysis with an effect size $r$ of $0.5, \alpha$ of 0.05 , and power of 0.95 ; the required sample size was determined to be 42 participants ( $G^{*}$ Power 3.1.9.7, Universität Kiel, Germany). All the analyses were performed using IBM SPSS 25.0 for Windows. The data were presented as mean \pm standard deviation (SD). An alpha of 0.05 was used to denote statistical significance, and the differences between the FQs and nonalcohol FQs were analyzed using the Student's paired $t$-test. For differences between the methods in the FQs, non-alcohol FQs, energy, protein, fat, carbohydrate, and alcohol were also analyzed using the Student's paired $t$-test (Tables 2 and 3). The FQs, non-alcohol FQs, energy, macronutrients, and alcohol according to the different sex and characteristics were analyzed using a one-way analysis of variance (ANOVA) (Tables 2 and 3). When a significant difference was detected, a multiple comparison test was performed using Tukey's posthoc test to determine the difference between groups. Differences between the weighted averages of previous studies and the averages of the present study were tested with paired-samples t-test. The relationships between the FQs or non-alcohol FQs from the DR and FQs or non-alcohol FQs from the FFQ were examined using Pearson's correlations.

\section{RESULTS}

The physical characteristics of the participants are 
Table 1. Characteristics of study participants.

\begin{tabular}{|c|c|c|c|c|}
\hline & \multicolumn{2}{|c|}{ Healthy young adult } & \multicolumn{2}{|c|}{ Runner } \\
\hline & Male $(n=9)$ & Female $(n=13)$ & Male $(n=11)$ & Female $(n=16)$ \\
\hline Age, y & $21.9 \pm 2.0$ & $22.4 \pm 2.2$ & $21.1 \pm 1.3$ & $19.6 \pm 1.2$ \\
\hline Body weight, kg & $65.0 \pm 9.6$ & $54.4 \pm 8.9$ & $60.5 \pm 5.9$ & $47.3 \pm 4.9$ \\
\hline Height, $\mathrm{cm}$ & $175.3 \pm 4.8$ & $162.5 \pm 6.5$ & $174.0 \pm 7.3$ & $158.2 \pm 4.4$ \\
\hline BMI, $\mathrm{kg} / \mathrm{m}^{2}$ & $21.1 \pm 2.8$ & $20.5 \pm 2.2$ & $19.9 \pm 0.9$ & $18.9 \pm 1.8$ \\
\hline $\mathrm{FM}, \mathrm{kg}$ & $10.4 \pm 4.6$ & $15.0 \pm 5.3$ & $5.1 \pm 1.3$ & $8.8 \pm 3.0$ \\
\hline FFM, kg & $54.6 \pm 5.5$ & $39.3 \pm 4.5$ & $55.4 \pm 5.1$ & $38.5 \pm 2.7$ \\
\hline
\end{tabular}

Physical characteristics in healthy young adults and runner. Mean \pm SD.

BMI, body mass index; FM, fat mass; FFM, fat-free mass.

\begin{tabular}{|c|c|c|c|c|c|}
\hline & Study & Methods & Age & $\mathbf{n}$ & $\begin{array}{c}\text { non-alcohol } \\
\text { FQ }\end{array}$ \\
\hline \multicolumn{3}{|c|}{ Healthy young adult } & \multicolumn{2}{|c|}{ weighted average } & 0.875 \\
\hline male & NHNS & $\mathrm{DR}$ & $20-29$ & 183 & 0.874 \\
\hline \multirow[t]{7}{*}{ female } & Kagawa $^{27}$ & BDHQ & $19.1 \pm 1.5$ & 100 & 0.881 \\
\hline & Hashimoto $^{28)}$ & DHQ & $20.5 \pm 2.0$ & 14 & 0.890 \\
\hline & Hashimoto $^{28)}$ & DHQ & $20.4 \pm 1.7$ & 33 & 0.883 \\
\hline & Hashimoto $^{28)}$ & DHQ & $20.4 \pm 2.0$ & 33 & 0.877 \\
\hline & Kawabata ${ }^{29)}$ & $\mathrm{DR}$ & about 20 & 25 & 0.877 \\
\hline & NHNS & $\mathrm{DR}$ & $20-29$ & 182 & 0.869 \\
\hline & & & \multicolumn{2}{|c|}{ female weighted average } & 0.876 \\
\hline \multicolumn{3}{|l|}{ Runner } & \multicolumn{2}{|c|}{ weighted average } & 0.879 \\
\hline \multirow[t]{4}{*}{ male } & Taguchi $^{30)}$ & $\mathrm{DR}$ & $19-21$ & 6 & 0.877 \\
\hline & Minato $^{31)}$ & DR & $19.4 \pm 1.1$ & 20 & 0.883 \\
\hline & Toyoshima $^{32)}$ & $\mathrm{DR}$ & $19.0 \pm 0.9$ & 6 & 0.878 \\
\hline & & \multicolumn{3}{|c|}{ male runner weighted average } & 0.881 \\
\hline \multirow[t]{5}{*}{ female } & Yoshida ${ }^{33)}$ & $\mathrm{DR}$ & $20.1 \pm 0.6$ & 9 & 0.887 \\
\hline & Ishibashi ${ }^{34)}$ & $\mathrm{DR}$ & $20.5 \pm 1.0$ & 16 & 0.874 \\
\hline & Koikawa $^{35)}$ & $\mathrm{DR}$ & $20.1 \pm 1.5$ & 8 & 0.878 \\
\hline & Koikawa $^{35)}$ & $\mathrm{DR}$ & $20.3 \pm 1.3$ & 8 & 0.872 \\
\hline & & \multicolumn{3}{|c|}{ female runner weighted average } & 0.877 \\
\hline \multicolumn{3}{|l|}{ Overall } & \multicolumn{2}{|c|}{ weighted average } & 0.876 \\
\hline
\end{tabular}

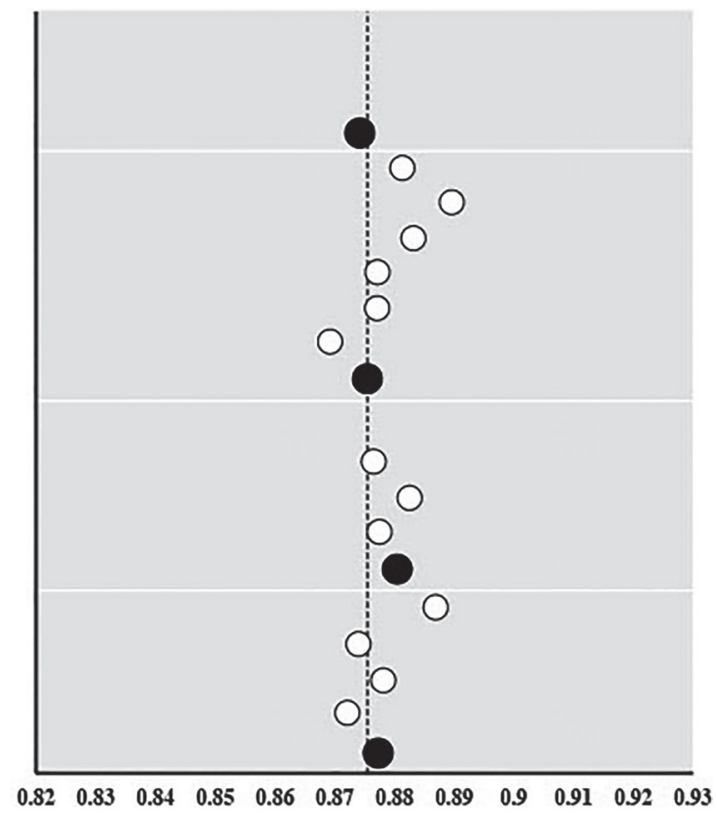

\begin{tabular}{|c|c|c|c|c|c|}
\hline & Study & Methods & Age & $\mathbf{n}$ & $\begin{array}{c}\text { non-alcohol } \\
\text { FQ }\end{array}$ \\
\hline male & \multirow{4}{*}{ present study } & $\mathrm{DR}$ & $21.9 \pm 2.0$ & 9 & 0.878 \\
\hline female & & $\mathrm{DR}$ & $19.6 \pm 1.2$ & 13 & 0.870 \\
\hline male runner & & $\mathrm{DR}$ & $21.1 \pm 1.3$ & 11 & 0.874 \\
\hline female runner & & $\mathrm{DR}$ & $22.4 \pm 2.2$ & 16 & $0.863^{*}$ \\
\hline Overall & & & & avera & 0.870 \\
\hline
\end{tabular}

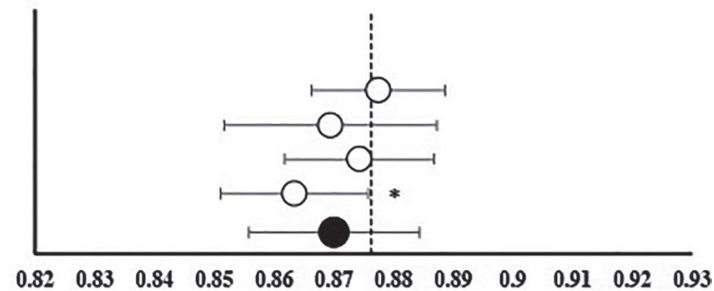

Fig. 1. Literature review of previous studies compared with the current study with respect to the non-alcohol FQs estimated by some dietary survey. The plot on the right figure corresponds to the non-alcohol FQ in the table on the left. The white plots show the non-alcohol FQ for each previous study, and the black plots show the weighted average of non-alcohol FQ for each group or average for present study. The non-alcohol FQ of the present study is shown in the right figure as mean \pm SD. Each reference number is indicated in the study name of the table on the left. FQ, food quotient; NHNS, Japan's National Health and Nutrition Examination Survey; DR, dietary record; BDHQ, brief-type self-administered diet history questionnaire; DHQ, self-administered diet history questionnaire. The dot lines show the weighted average of non-alcohol $\mathrm{FQ}$ calculated from all previous studies. ${ }^{*} p<0.05$ vs. female runner weighted average from previous publications.

shown in Table 1 . The mean age was $21.1 \pm 2.0 \mathrm{y}$ (range: 18 to $25 \mathrm{y}$ ). The mean body weight was $55.4 \pm$ $9.8 \mathrm{~kg}$ and the mean height was $166.0 \pm 9.3 \mathrm{~cm}$. The mean BMI was $20.0 \pm 2.1 \mathrm{~kg} / \mathrm{m}^{2}$.

Figure 1 shows the comparison of previous and cur- rent studies on non-alcohol FQs estimated from some dietary assessments. The non-alcohol FQ from previous studies, using the weighted average of healthy young adults was 0.875 (male: 0.874 , female: 0.876) (2729 ), and of runners was 0.879 (male: 0.881 , female: 
Table 2. Comparison of energy, macronutrients and alcohol estimated by dietary record and food frequency questionnaire.

\begin{tabular}{|c|c|c|c|c|}
\hline & \multicolumn{2}{|c|}{ Healthy young adult } & \multicolumn{2}{|c|}{ Runner } \\
\hline & Male $(n=9)$ & Female $(n=11)$ & Male $(n=11)$ & Female $(n=16)$ \\
\hline \multicolumn{5}{|l|}{ Dietary record } \\
\hline Energy, kcal & $1,829 \pm 360$ & $1,619 \pm 256$ & $2,070 \pm 337^{\dagger}$ & $1,889 \pm 358$ \\
\hline $\begin{array}{l}\text { Protein, } g \\
\quad(\%)\end{array}$ & $\begin{array}{c}66.8 \pm 12.3 \\
(14.8)\end{array}$ & $\begin{array}{c}60.5 \pm 10.7^{\dagger} \\
(15.1)\end{array}$ & $\begin{array}{l}81.7 \pm 16.1^{\dagger} \\
\quad(15.9)\end{array}$ & $\begin{array}{c}78.2 \pm 14.4 \\
(16.6)\end{array}$ \\
\hline $\begin{array}{r}\text { Fat, } g \\
(\%)\end{array}$ & $\begin{array}{c}62.7 \pm 12.6 \\
(31.2)\end{array}$ & $\begin{array}{c}60.0 \pm 11.7 \\
(33.8)\end{array}$ & $\begin{array}{c}72.0 \pm 7.9 \\
(31.4)\end{array}$ & $\begin{array}{c}73.0 \pm 16.9 \\
(34.9)\end{array}$ \\
\hline $\begin{array}{l}\text { Carbohydrate, g } \\
\quad(\%)\end{array}$ & $\begin{array}{c}260 \pm 57.5 \\
(54.0)\end{array}$ & $\begin{array}{l}218 \pm 46.4 \\
(51.1)\end{array}$ & $\begin{array}{c}290 \pm 64.8^{\dagger} \\
(52.7)\end{array}$ & $\begin{array}{c}243 \pm 51.0 \\
(48.4)\end{array}$ \\
\hline $\begin{array}{l}\text { Alcohol, g } \\
\quad(\%)\end{array}$ & $\begin{array}{l}3.2 \pm 5.0 \\
(1.2)\end{array}$ & $\begin{array}{c}2.9 \pm 6.0 \\
(1.3)\end{array}$ & $\begin{array}{c}1.3 \pm 0.5 \\
(0.4)\end{array}$ & $\begin{array}{c}1.3 \pm 0.9 \\
(0.5)\end{array}$ \\
\hline \multicolumn{5}{|c|}{ Food frequency questionnaire } \\
\hline Energy, kcal & $1,598 \pm 315$ & $1,462 \pm 262$ & $2,082 \pm 422^{\dagger}$ & $1,848 \pm 704$ \\
\hline $\begin{array}{l}\text { Protein, } g \\
(\%)\end{array}$ & $\begin{array}{c}58.3 \pm 16.1 \\
(14.9)\end{array}$ & $\begin{array}{c}54.9 \pm 9.5 \\
(15.3)\end{array}$ & $\begin{array}{c}79.3 \pm 15.1^{\dagger} \\
(15.3)\end{array}$ & $\begin{array}{c}75.5 \pm 29.6 \\
(16.4)\end{array}$ \\
\hline $\begin{array}{r}\text { Fat, } g \\
(\%)\end{array}$ & $\begin{array}{c}54.9 \pm 15.4 \\
(31.6)\end{array}$ & $\begin{array}{c}54.8 \pm 12.2 \\
(34.5)\end{array}$ & $\begin{array}{c}72.5 \pm 17.3 \\
(31.5)\end{array}$ & $\begin{array}{c}76.3 \pm 32.5 \\
(37.2)\end{array}$ \\
\hline $\begin{array}{l}\text { Carbohydrate, } g \\
(\%)\end{array}$ & $\begin{array}{c}223 \pm 41.1 \\
(53.5)\end{array}$ & $\begin{array}{c}192 \pm 49.7 \\
(50.2)\end{array}$ & $\begin{array}{c}293 \pm 61.9^{\dagger} \\
(53.1)\end{array}$ & $\begin{array}{c}229 \pm 85.5 \\
(46.5)\end{array}$ \\
\hline $\begin{array}{l}\text { Alcohol, g } \\
\text { (\%) }\end{array}$ & $\begin{array}{c}4.7 \pm 7.8 \\
(2.1)\end{array}$ & $\begin{array}{c}4.5 \pm 7.3 \\
(2.2)\end{array}$ & $\begin{array}{c}1.8 \pm 2.5 \\
(0.6)\end{array}$ & $\begin{array}{c}0.2 \pm 0.2^{*} \\
(0.1)\end{array}$ \\
\hline
\end{tabular}

Mean \pm SD.

* Significant differences between dietary record and food frequency questionnaire $(p<0.05)$.

${ }^{\dagger}$ Significant differences vs. female runner, $p<0.05$.

Table 3. Comparison of FQs and non-alcohol FQs estimated by dietary record and food frequency questionnaire.

\begin{tabular}{|c|c|c|c|c|}
\hline & \multicolumn{2}{|c|}{ Healthy young adult } & \multicolumn{2}{|c|}{ Runner } \\
\hline & Male $(n=9)$ & Female $(n=11)$ & Male $(n=11)$ & Female $(n=16)$ \\
\hline \multicolumn{5}{|l|}{ Dietary record } \\
\hline $\mathrm{FQ}$ & $\begin{array}{c}0.875 \pm 0.011 \\
(0.856-0.890)\end{array}$ & $\begin{array}{c}0.867 \pm 0.018 \\
(0.822-0.886)\end{array}$ & $\begin{array}{c}0.873 \pm 0.012 \\
(0.854-0.891)\end{array}$ & $\begin{array}{c}0.863 \pm 0.012 \\
(0.832-0.881)\end{array}$ \\
\hline Non-alcohol FQ & $\begin{array}{c}0.878 \pm 0.011 \\
(0.857-0.892)\end{array}$ & $\begin{array}{c}0.870 \pm 0.018 \\
(0.823-0.888)\end{array}$ & $\begin{array}{c}0.874 \pm 0.013 \\
(0.855-0.892)\end{array}$ & $\begin{array}{c}0.863 \pm 0.012 \\
(0.833-0.882)\end{array}$ \\
\hline \multicolumn{5}{|c|}{ Food frequency questionnaire } \\
\hline FQ & $\begin{array}{c}0.873 \pm 0.011 \\
(0.864-0.892)\end{array}$ & $\begin{array}{c}0.862 \pm 0.021 \\
(0.824-0.888)\end{array}$ & $\begin{array}{l}0.875 \pm 0.011^{\dagger} \\
(0.859-0.893)\end{array}$ & $\begin{array}{c}0.859 \pm 0.013 \\
(0.839-0.880)\end{array}$ \\
\hline Non-alcohol FQ & $\begin{array}{l}0.878 \pm 0.013^{\dagger} \\
(0.866-0.897)\end{array}$ & $\begin{array}{c}0.866 \pm 0.020 \\
(0.824-0.888)\end{array}$ & $\begin{array}{l}0.876 \pm 0.010^{\dagger} \\
(0.859-0.893)\end{array}$ & $\begin{array}{c}0.859 \pm 0.013 \\
(0.840-0.880)\end{array}$ \\
\hline \multicolumn{5}{|l|}{$p$ Value * } \\
\hline $\mathrm{FQ}$ & 0.689 & 0.388 & 0.761 & 0.306 \\
\hline Non-alcohol FQ & 0.876 & 0.584 & 0.736 & 0.210 \\
\hline
\end{tabular}

Mean \pm SD. Each range values are noted in brackets. FQ, food quotient.

* Statistical analysis was using paired $t$-test to compare the methods of FQ and non-alcohol FQ calculated by DR and FFQ.

† Significant differences vs. female runner, $p<0.05$. 

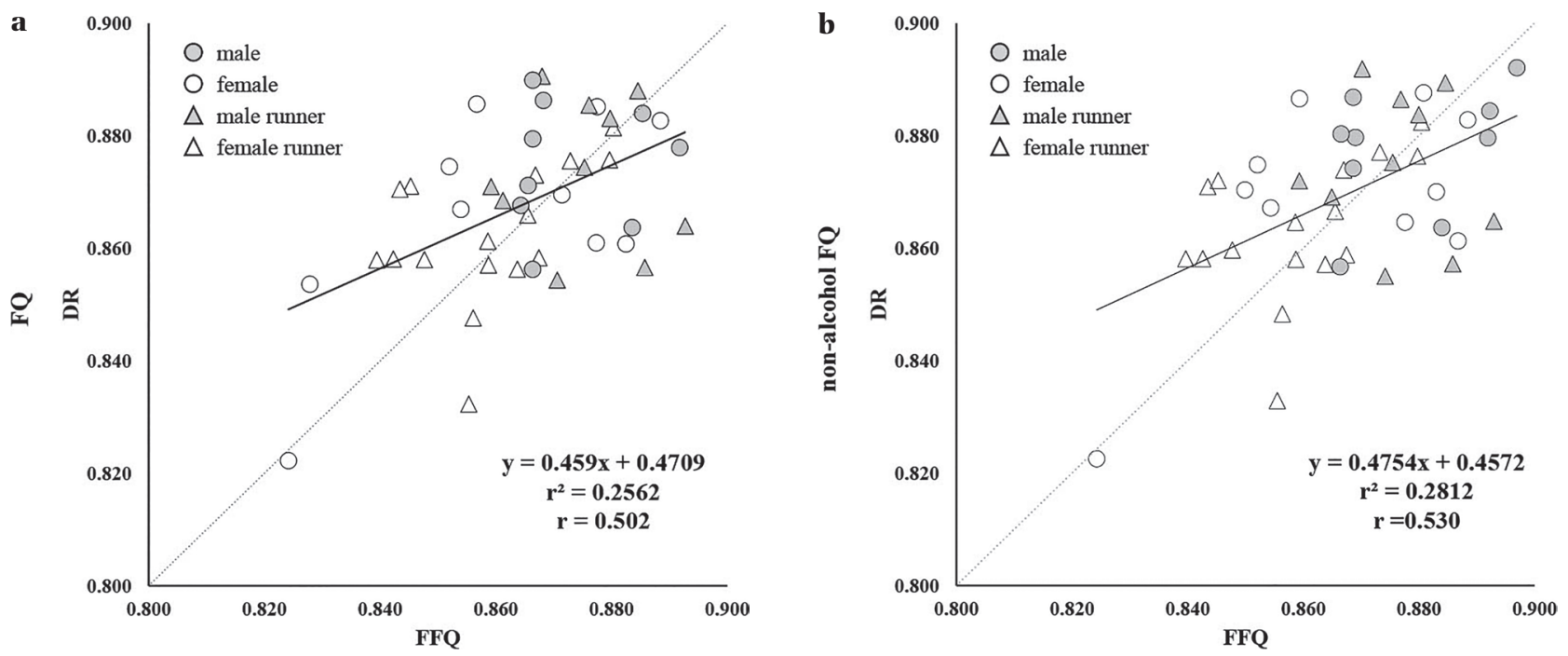

Fig. 2. a: Relationship between the FQs estimated using the DR and FQs estimated with the FFQ. b: Relationship between the non-alcohol FQs estimated using the DR and non-alcohol FQs estimated with the FFQ. Circles indicate healthy young adults (male is gray, female is white), and triangles indicate runners (male is gray, female is white). FQ, food quotient; DR, dietary records; FFQ, food frequency questionnaire.

0.877 ) (30-35). The overall weighted average from previous studies was 0.876 . In the present study, the overall average of the non-alcohol FQ was 0.870. The non-alcohol FQ in female runner groups between previous and current studies was significantly different $(p<$ $0.05)$.

Table 2 shows the comparison of energy, protein, fat, carbohydrate, and alcohol estimated using the DR and FFQ in healthy young adults and runner. There were no significant differences for energy, protein, fat, and carbohydrate between the estimation methods for all the groups; however, the alcohol estimated using the FFQ was lower than that estimated using the DR in female runners $(p<0.05)$. In the female runner group, protein, carbohydrate, and energy estimated using the DR and FFQ were significantly lower than in the male runner group $(p<0.05)$. The protein estimated using the DR in the healthy young female group was lower than in the female runner group $(p<0.05)$; however, the protein estimated using the FFQ did not differ between the healthy young female and female runner groups $(p=$ 0.071).

Table 3 shows the comparison of the FQs and non-alcohol FQs estimated using the DR and FFQ in healthy young adults and runners. The FQ of healthy young adults was 0.871 (male: 0.875 , female: 0.867 ), and the FQ of runners was 0.867 (male: 0.873 , female: 0.863 ) in this study. There were no differences in the FQs and non-alcohol FQs between the estimation methods for all the groups. There was a significant correlation between the FQs estimated using the DR and FQs estimated with the FFQ (slope 0.4590, intercept 0.4709, $r=0.502, p<$ 0.01) (Fig. 2a) and between the non-alcohol FQs estimated using the DR and non-alcohol FQs estimated with the FFQ (slope 0.4754, intercept 0.4572, $r=$ 0.530, $p<0.01$ ) (Fig. 2b). The FQs and non-alcohol FQs estimated using the DR showed no differences between all the groups. In contrast, the FQs estimated using the FFQ of the female runner group were lower than in the male runner group $(p<0.05)$, and the non-alcohol FQs estimated using the FFQ in the female runner group were lower than in the healthy young male and male runner group $(p<0.05)$. A post-hoc power calculation was also conducted, and the result was 0.98 for all correlations.

\section{DISCUSSION}

The FQ is an indicator that can be used to estimate the oxidative substrates from the meal and to calculate the energy expenditure from DLW methods. However, there have been few studies showing the average value of the FQs for healthy young adults, especially Japanese athletes. This is the first study to indicate the FQs of healthy young adults (current study: 0.871) and runners (current study: 0.867), and the non-alcohol FQs of healthy young adults (previous study: 0.875, current study: 0.873) and runners (previous study: 0.879, current study: 0.868) (Fig. 1, Table 3). We also compared the DR and FFQ methods to examine whether the FFQ is useful in the calculation of the FQ. There were no differences in the FQs between the methods for all groups, and there was a significant moderate correlation between these methods (Tables 2 and 3, Fig. 2).

In this study, the FQ and non-alcohol FQ calculated from the DR for the male runners were 0.873 and 0.874, respectively, while the FQ and non-alcohol FQ calculated from DR for the female runners were both 0.863. The weighted averages of the non-alcohol FQs from the previous studies for the male and female runners were 0.881 and 0.877 , respectively (30-35). The non-alcohol FQ of the female runner group in the present study was significantly lower than the weighted average of the non-alcohol FQs that were shown in previous studies (Fig. 1). The athletic season was divided 
into four periods: pre-season, in-season, post-season, and off-season, with training and diet differing depending on the period; carbohydrate intake being especially low in the off-season when the training volume was reduced (36). The criteria for the inclusion of the literature reviewed in this study were race, age, gender, runner, and the absence of dietary interventions. Therefore, since the timing of the dietary assessments was not standardized, the differences in the non-alcohol FQs among the female runner groups may have occurred due to differences in the timing of the surveys. In addition, recent studies have shown that a high-carbohydrate diet is recommended for endurance runners (18, 37 ), and some runners were conscious of eating more carbohydrates in their daily diets. In those cases, the FQ and non-alcohol FQ show relatively higher values. Since studies of runners had fewer participants, they were likely to be influenced by team and/or individual dietary policies. Therefore, to obtain more accurate assessments, it is necessary to investigate $\mathrm{FQ}$ and non-alcohol FQ according to periodization because the dietary composition for athletes may change.

There was a significant correlation between the FQs estimated using the DR and the FQs estimated with the FFQ $(r=0.502, p<0.01)$ (Fig. 2a). There was also a significant correlation between the non-alcohol FQs estimated using the DR and non-alcohol FQs estimated with the FFQ $(r=0.530, p<0.01)$ (Fig. 2b). The correlation coefficient should be 0.5 or higher to assess the validity of the dietary assessments (38), and systematic reviews have reported there were moderate correlations for energy and macronutrients between FFQ and DR (24). The correlation coefficients of FQ and non-alcohol FQ were higher than 0.5, and the calculation of FQ and non-alcohol FQ in FFQ was validated. The FQs estimated using the FFQ in the female runner group was lower than the FQs in the male runner group $(p<0.05)$, and the non-alcohol FQs estimated using the FFQ in the female runner group were lower than the non-alcohol FQs in the healthy young male and male runner group $(p<0.05)$ (Table 3). The differences in only the FQs and non-alcohol FQs calculated using the FFQ may have been due to the differences in alcohol volumes among the assessment methods in the female athlete group (Table 2). They may have had a small effect on the FQs even though these differences were small. Although few participants had been drinking during the study period, the healthy young adult groups had more drinkers than the runner groups, and the differences between the FQs and non-alcohol FQs were also larger compared to that of the runner groups. However, the coefficient for alcohol in the calculation of the FQ was 0.67 , which indicated that the effect of alcohol on the FQ was negligible, as it has the least effect on the FQ compared with protein, fat, and carbohydrate (7). The RQ was not assessed in this study; thus, it was not possible to determine whether the FQ or non-alcohol FQ was closer to the RQ; nevertheless, there may have been participants who drank heavily for the FQ calculation. Moreover, this may have affected the interindividual variability of the protein, fat, and especially the carbohydrate levels in the female runner groups on the calculation of the FFQ. The carbohydrate is the most influential factor for the FQ because its coefficient is 1.00. The interindividual SDs of protein, fat, and carbohydrate estimated using the FFQ in female runners were 29.6, 32.5, and 85.5, respectively, which were larger than the values of the other three groups and the values calculated using the DR (Table 2). The large inter-individual variability of protein, fat, and carbohydrate among the female runners may have affected the FQ and non-alcohol FQ, although there were no significant differences between the estimation methods in this study. Most Japanese eat rice, mainly as a staple food and as a source of carbohydrates. Rice was counted as "one light cup (150 g) in a rice bowl=one" in the FFQ (FFQg ver. 5) in this study, and this coefficient may be improved if it was calculated according to the type of participants, the amount of intake, and DR. The volume of rice for female runners in this study was less than $150 \mathrm{~g}$ or it greatly exceeded it, and it was possible that the participants could not convert the coefficients according to the amount of intake. Instead, it required multiple portion sizes for athletes. The FFQ used in this study was a questionnaire designed for non-athletes, and the more detailed questions required for athletes were not included. Therefore, it may be preferable to use a questionnaire designed for athletes to minimize the number of errors made by the participants (39).

There were no differences between the two methods; the intra-individual variation (SD) was 0.011 for the two different methods. This variation may have affected the TEE by within 1\% (25). This result was supported by a previous study that investigated the variations between the four dietary methods (25). The intra-individual differences between the methods of FQ and nonalcohol FQ were 0.000-0.029. Hence, the difference in the TEE was less than $80 \mathrm{kcal} / \mathrm{d}$ between the FQs $(0.86$ and 0.89 ) in a female runner of $45 \mathrm{~kg}$ (TEE=2,862 $\mathrm{kcal} / \mathrm{d}$ ) when we simulated the maximum difference of 0.03 for the FQ value for the TEE using the DLW method. This difference would have resulted in a difference of approximately $2.7 \%$ in the TEE, which was slightly larger for most DLW applications, though it represented an acceptable estimate of the physiological variation in the TEE of approximately 7\% (40-42). Therefore, while it is better to confirm the FQ using the FFQ, it is not necessary to use the one-week DR for DLW studies on runners.

There were some limitations to this study. First, the results of the DR may have measurement errors approximately $20 \%$ (43). However, energy substrate should be evaluated by DR, and we performed the same procedure as that used a previous study (25). The percentages of protein, fat, and carbohydrate calculated by DR for healthy young adults in the present study were comparable to the results of the National Health and Nutrition Examination Survey; thus, the results of this study calculated by DR are valid. It may be desirable to perform a calibration using DLW and $24 \mathrm{~h}$ RQ in the 
future to reduce the estimation errors caused by DR. Second, female runners were not classified and examined according to their types of menstrual cycles. Among the 16 participants, there were normal menstruation, irregularity of menstruation, and amenorrhea. Third, although most of this research was done in the off-season, the study period was not standardized for runners. Finally, the training and diets of the runner may have showed differences depending on the period. Therefore, we recommend the validation of the FQ and non-alcohol FQ by periodization in future studies.

Overall, the FQ allows for easy evaluation of energy substrates without measuring RQ. We also recommend using a FQ of 0.87 to 0.88 as a constant reference value when calculating the TEE for young Japanese adults and runners using the DLW method. It was noted that individual FQ calculations were better when considering the eating habits of runners following extreme diets such as low or high carbohydrate diets. The investigation methods may have been adequate using the FFQ because the effects of the different FQs on the TEE between the different methods was negligible. The use of FFQ for FQ calculations may reduce the burden and time on participants and dietitians. We believe this will help in devising dietary plans for people including athletes. This approach could be also further our understanding on DLW research.

\section{Authorship}

AU and HS: study conception and design; AU, AF, HO, YE and SZ: conduction of experiments; AU and AF: data analysis; AU and HS: interpretation of experimental results; AU and HS: preparation of illustrations; AU and HS: drafting of manuscript; AU, KT, NO, and HS: editing and revising manuscript. All authors read and approved the final version of the manuscript.

\section{Disclosure of state of COI}

No conflicts of interest to be declared.

\section{Acknowledgments}

We wish to thank the volunteers who participated in this study. The authors would also like to thank Dr. Emi Kondo and Mr. Yoshiaki Tanaka for comments on earlier version of this paper.

The data analysis and draft writing was supported by a Research Fellowships of the JSPS for Young Scientists Research Grant (20K19563; to HS) and University of Tsukuba Basic Research Support Program Type S.

\section{REFERENCES}

1) Schoeller DA, Santen E Van. 1982. Measurement of energy expenditure in humans by doubly labeled water method. J Appl Physiol 53(4): 955-959.

2) Sagayama H, Hamaguchi G, Toguchi M, Ichikawa M, Yamada Y, Ebine N, Higaki Y, Tanaka H. 2017. Energy requirement assessment in Japanese table tennis players using the doubly labeled water method. Int J Sport Nutr Exerc Metab 27(5): 421-428.

3) Speakman JR, Yamada Y, Sagayama H, Berman ESF, Ainslie PN, Andersen LF, Anderson LJ, Arab L, Baddou
I, Bedu-Addo K, Blaak EE, Blanc S, Bonomi AG, Bouten CVC, Bovet P, Buchowski MS, Butte NF, Camps SGJA, Close GL, Cooper JA, Creasy SA, Das SK, Cooper R, Dugas LR, Ebbeling CB, Ekelund U, Entringer S, Forrester T, Fudge BW, Goris AH, Gurven M, Hambly C, Hamdouchi AEl, Hoos MB, Hu S, Joonas N, Joosen AM, Katzmarzyk P, Kempen KP, Kimura M, Kraus WE, Kushner RF, Lambert EV, Leonard WR, Lessan N, Ludwig DS, Martin CK, Medin AC, Meijer EP, Morehen JC, Morton JP, Neuhouser ML, Nicklas TA, Ojiambo RM, Pietiläinen KH, Pitsiladis YP, Plange-Rhule J, Plasqui G, Prentice RL, Rabinovich RA, Racette SB, Raichlen DA, Ravussin E, Reynolds RM, Roberts SB, Schuit AJ, Sjödin AM, Stice E, Urlacher SS, Valenti G, Etten LM Van, Mil EA Van, Wells JCK, Wilson G, Wood BM, Yanovski J, Yoshida T, Zhang X, Murphy-Alford AJ, Loechl CU, Melanson EL, Luke AH, Pontzer H, Rood J, Schoeller DA, Westerterp KR, Wong WW, IAEA DLW Database Group. 2021. A standard calculation methodology for human doubly labeled water studies. Cell Rep Med 2(2): 100203.

4) Speakman JR, Pontzer H, Rood J, Sagayama H, Schoeller DA, Westerterp KR, Wong WW, Yamada Y, Loechl C, Murphy-Alford AJ. 2019. The International Atomic Energy Agency International Doubly Labelled Water Database: Aims, scope and procedures. Ann Nutr Metab 75(2): 114-118.

5) Sagayama H, Yamada Y, Racine NM, Shriver TC, Schoeller DA. 2016. Dilution space ratio of $2 \mathrm{H}$ and 180 of doubly labeled water method in humans. J Appl Physiol 120(11): 1349-1354.

6) International Atomic Energy Agency. 2009. Assessment of Body Composition and Total Energy Expenditure in Humans Using Stable Isotope Technique. IAEA Human Health Series, No. 3.

7) Black AE, Prentice AM, Coward WA. 1986. Use of food quotients to predict respiratory quotients for the doubly-labelled water method of measuring energy expenditure. Hum Nutr Clin Nutr 40(5): 381-391.

8) Westerterp KR. 1993. Respiratory quotient, and energy. Distribution 57(5 Suppl): 759S-764S; discussion 764 S$765 \mathrm{~S}$.

9) Kant AK. 2002. Nature of dietary reporting by adults in the Third National Health and Nutrition Examination Survey, 1988-1994. J Am Coll Nutr 21(4): 315-327.

10) Thomson M, Logan RL, Sharman M, Lockerbie L, Riemersma RA, Oliver MF. 1982. Dietary survey in 40year-old Edinburgh men. Hum Nutr Appl Nutr 36A(4): 272-280.

11) Brown ML, Worth RM, Shah NK. 1968. Food habits and food intake in Nepal. Trop Geogr Med 20(3): 217-224.

12) Ishikawa-Takata K, Tabata I, Sasaki S, Rafamantanantsoa HH, Okazaki H, Okubo H, Tanaka S, Yamamoto S, Shirota T, Uchida K, Murata M. 2008. Physical activity level in healthy free-living Japanese estimated by doubly labelled water method and International Physical Activity Questionnaire. Eur J Clin Nutr 62(7): 885-891.

13) Yamada Y, Noriyasu R, Yokoyama K, Osaki T, Adachi T, Itoi A, Morimoto T, Oda S, Kimura M. 2013. Association between lifestyle and physical activity level in the elderly: A study using doubly labeled water and simplified physical activity record. Eur J Appl Physiol 113(10): 2461-2471.

14) Murakami K, Livingstone MBE, Sasaki S. 2018. Thirteen-year trends in dietary patterns among Japanese adults in the National Health and Nutrition Survey 
2003-2015: Continuous westernization of the Japanese diet. Nutrients 10(8): 994-1009.

15) Witard OC, Garthe I, Phillips SM. 2019. Dietary protein for training adaptation and body composition manipulation in track and field athletes. Int J Sport Nutr Exerc Metab 29(2): 165-174.

16) Burke LM, Ross ML, Garvican-Lewis LA, Welvaert M, Heikura IA, Forbes SG, Mirtschin JG, Cato LE, Strobel N, Sharma AP, Hawley JA. 2017. Low carbohydrate, high fat diet impairs exercise economy and negates the performance benefit from intensified training in elite race walkers. J Physiol 595(9): 2785-2807.

17) Burke LM. 2015. Re-examining high-fat diets for sports performance: Did we call the 'nail in the coffin' too soon? Sports Med 45(Suppl 1): S33-S49.

18) Cole M, Coleman D, Hopker J, Wiles J. 2014. Improved gross efficiency during long duration submaximal cycling following a short-term high carbohydrate diet. Int J Sports Med 35(3): 265-269.

19) Ortega RM, Perez-Rodrigo C, Lopez-Sobaler AM. 2015. Métodos de evaluación de la ingesta actual: Registro o diario dietético. Nutr Hosp 31: 38-45.

20) Wakai K. 2009. A review of food frequency questionnaires developed and validated in Japan. J Epidemiol 19(1): 1-11.

21) Sasaki S, Yanagibori R, Amano K. 1998. Self-administered diet history questionnaire developed for health education: A relative validation of the test-version by comparison with 3-day diet record in women. J Epidemiol 8(4): 203-215.

22) Lopes C, Torres D, Oliveira A, Severo M, Guiomar S, Alarcão V, Ramos E, Rodrigues S, Vilela S, Oliveira L, Mota J, Teixeira PJ, Nicola PJ, Soares S, Andersen LF. 2018. National food, nutrition, and physical activity survey of the Portuguese general population (20152016): Protocol for design and development. JMIR Res Protoc 7(2): 1-12.

23) Sasaki S, Mi-Kyung K. 2003. Validation of self-administered dietary assessment questionnaires developed for Japanese subjects: Systematic review. J Community Nutr 5(2): 83-92.

24) Cade JE, Burley VJ, Warm DL, Thompson RL, Margetts BM. 2004. Food-frequency questionnaires: a review of their design, validation and utilisation. Nutr Res Rev 17(1): 5-22.

25) Surrao J, Sawaya AL, Dallal GE, Tsay R, Roberts SB. 1998. Use of food quotients in human doubly labeled water studies: Comparable results obtained with 4 widely used food intake methods. J Am Diet Assoc 98(9): 1015-1020.

26) Takahashi K, Yoshimura Y, Kaimoto T, Kunii D, Komatsu T, Yamamoto S. 2001. Validation of a food frequency questionnaire based on food groups for estimating individual nutrient intake. Jpn J Nutr Diet 59(5): 221-232.

27) Kagawa M, Hills AP. 2020. Preoccupation with body weight and under-reporting of energy intake in female Japanese nutrition students. Nutrients 12(3): 1-13.

28) Hashimoto A, Inoue H, Kuwano T. 2020. Low energy intake and dietary quality are associated with low objective sleep quality in young Japanese women. Nutr Res 80: $44-54$.

29) Kawabata T, Hyogo H, Hagiwara C, Matsuzaki S, Shinjo S. 2008. Intake of trans fatty acids estimated by direct dietary measurement in young women. Jpn Soc Nutr Food Sci 61(4): 161-168.

30) Taguchi M, Moto K, Lee S, Torii S, Hongu N. 2020. Energy intake deficiency promotes bone resorption and energy metabolism suppression in Japanese male endurance runners: A pilot study. Am J Mens Health 14(1): 1557988320905251.

31) Minato K, Sato Y, Kobayashi S, Kariya F, Kobayashi K, Narusawa M, Ohmori T. 2006. Nutritional status of Japanese male collegiate athletes. Jpn J Phys Fit Sport Med 55(Suppl): S189-S192.

32) Toyoshima T, Inoshita K, Ishii T, Nakano S, Ito T. 2005. Relation between body composition and physical athletic performance of long distance relay runners produced by a four week weight loss program. Jpn J Phys Fit Sport Med 54(1): 87-97.

33) Yoshida A, Ishikawa-Takata K, Bessho K, Taguchi M, Tatsuta W, Totani M, Higuchi M. 2012. Factors associated with reporting error for energy intake estimated by food records in female athletes. Jpn J Nutr Diet 70(5): 305-315.

34) Ishibashi A, Maeda N, Sumi D, Goto K. 2017. Elevated serum hepcidin levels during an intensified training period in well-trained female long-distance runners. Nutrients 9(3): 277-285.

35) Koikawa N, Nagaoka I, Yamaguchi M, Hamano H, Yamauchi K, Sawaki K. 2008. Preventive effect of lactoferrin intake on anemia in female long distance runners. Biosci Biotechnol Biochem 72(4): 931-935.

36) Heikura IA, Stellingwerff T, Burke LM. 2018. Self-reported periodization of nutrition in elite female and male runners and race walkers. Front Physiol 9(December): 1-16.

37) Erlenbusch M, Haub M, Munoz K, MacConnie S, Stillwell B. 2005. Effect of high-fat or high-carbohydrate diets on endurance exercise: A meta-analysis. Int J Sport Nutr Exerc Metab 15(1): 1-14.

38) Kameda S, Sudo N. 2021. A systematic review of food frequency questionnaire developed for Japanese and examined the validity. Jpn J Heal Hum Ecol 87(1): 3-14.

39) Ishikawa-Takata K, Okamoto K, Taguchi M. 2021. Development and validation of a food frequency questionnaire for Japanese athletes (FFQJA). J Int Soc Sports Nutr 18(1): 1-13.

40) Ritz P, Cole TJ, Couet C, Coward WA. 1996. Precision of DLW energy expenditure measurements: contribution of natural abundance variations. Am J Physiol Metab 270(1): E164-E169.

41) Goldberg GR, Prentice AM, Coward WA, Davies HL, Murgatroyd PR, Wensing C, Black AE, Harding M, Sawyer M. 1993. Longitudinal assessment of energy expenditure in pregnancy by the doubly labeled water method. Am J Clin Nutr 57(4): 494-505.

42) Cole TJ, Coward WA. 1992. Precision and accuracy of doubly labeled water energy expenditure by multipoint and two-point methods. Am J Physiol-Endocrinol Metab 263(5): E965-E973.

43) Sagayama H, Kondo E, Shiose K, Yamada Y, Motonaga K, Ouchi S, Kamei A, Osawa T, Nakajima K, Takahashi H, Higaki Y, Tanaka H. 2017. Energy requirement assessment and water turnover in Japanese college wrestlers using the doubly labeled water method. J Nutr Sci Vitaminol 63(2): 141-147. 